\title{
Optoelectronically Optimized Colored Thin-Film Solar Cells
}

\author{
Ahmad, Faiz; Anderson, Tom H.; Lenau, Torben; Lakhtakia, Akhlesh
}

Published in:

Proceedings of SPIE

Link to article, DOI:

$10.1117 / 12.2534592$

Publication date:

2019

Document Version

Publisher's PDF, also known as Version of record

Link back to DTU Orbit

Citation (APA):

Ahmad, F., Anderson, T. H., Lenau, T., \& Lakhtakia, A. (2019). Optoelectronically Optimized Colored Thin-Film Solar Cells. In P. Banerjee, K. Gudmundsson, A. Lakhtakia, \& G. Subramany (Eds.), Proceedings of SPIE (Vol. 11371). [1137107] SPIE - International Society for Optical Engineering. https://doi.org/10.1117/12.2534592

\section{General rights}

Copyright and moral rights for the publications made accessible in the public portal are retained by the authors and/or other copyright owners and it is a condition of accessing publications that users recognise and abide by the legal requirements associated with these rights.

- Users may download and print one copy of any publication from the public portal for the purpose of private study or research.

- You may not further distribute the material or use it for any profit-making activity or commercial gain

- You may freely distribute the URL identifying the publication in the public portal

If you believe that this document breaches copyright please contact us providing details, and we will remove access to the work immediately and investigate your claim. 


\section{Optoelectronically optimized colored thin-film CZTSSe solar cells}

Ahmad, Faiz, Anderson, Tom, Lenau, Torben, Lakhtakia, Akhlesh

Faiz Ahmad, Tom H. Anderson, Torben Lenau, Akhlesh Lakhtakia, "Optoelectronically optimized colored thin-film CZTSSe solar cells," Proc. SPIE 11371, International Workshop on Thin Films for Electronics, ElectroOptics, Energy, and Sensors 2019, 1137107 (6 December 2019); doi: 10.1117/12.2534592

Event: International Workshop on Thin Films for Electronics, Electro-Optics, Energy and Sensors, 2019, Reykjavik, Iceland 


\title{
Optoelectronically optimized colored thin-film CZTSSe solar cells
}

\author{
Faiz Ahmad $^{a}$, Tom H. Anderson ${ }^{b}$, Torben Lenau ${ }^{c}$, and Akhlesh Lakhtakia ${ }^{a}$ \\ ${ }^{a}$ Pennsylvania State University, Department of Engineering Science and Mechanics, \\ University Park, PA 16802, USA \\ ${ }^{b}$ University of Delaware, Department of Mathematical Sciences, Newark, DE 19716, USA \\ ${ }^{c}$ Technical University of Denmark, Department of Mechanical Engineering, \\ DK-2800 Lyngby, Denmark
}

\begin{abstract}
Rooftop solar cells may become more acceptable if they are colored, e.g., red or blue-green, which requires that a certain part of the incoming solar spectrum be reflected. We implemented and optimized an optoelectronic model for $\mathrm{Cu}_{2} \mathrm{ZnSn}\left(\mathrm{S}_{\xi} \mathrm{Se}_{1-\xi}\right)_{4}$ (CZTSSe) solar cells containing (i) a conventional 2200-nm-thick CZTSSe layer with homogeneous bandgap, or (ii) an ultrathin CZTSSe layer with optoelectronically optimized sinusoidally nonhomogeneous bandgap, or (iii) a CZTSSe layer with optoelectronically optimized linearly nonhomogeneous bandgap. Either complete or partial rejection of either red or blue-green photons was incorporated in the model. Calculations show that on average, the efficiency of a typical solar cell will be reduced by about $9 \%$ if $50 \%$ red photons are reflected or by about $13 \%$ if $50 \%$ blue-green photons are reflected. The efficiency reduction increases to about $18 \%$ if all red photons are reflected or about $26 \%$ if all blue-green photons are reflected.
\end{abstract}

Keywords: colored solar cell, CZTSSe, optoelectronic optimization, thin-film solar cell

\section{INTRODUCTION}

Photovoltaic solar cells represent an eco-friendly source of energy. However, they take up valuable land that otherwise could be used for other purposes such as farming. Rooftops are promising alternatives since they have the only function. But, many houseowners and their tenants appreciate the aesthetic appearance of their living and working spaces, and some of them resist the installation of solar panels on rooftops due to visual change. ${ }^{1}$ Solar cells are typically bluish black and have macroscopically uniform flat surfaces, those features providing the maximum energy output. Roof claddings, such as red clay tiles, are often colored and have corrugated surfaces, in contrast. The aesthetic requirements can be met by coloring solar cells either red or blue-green.

Red or blue-green rejection filters can be made of particulate composite materials containing, say, silica nanospheres. Typically, the solar cells will be iridescent then, which may not be aesthetically pleasing to many. Non-iridescent colored rejection filters can be fabricated by properly scaling the linear dimensions of biomimetic filters nano-imprinted to reproduce the Morpho blue, ${ }^{2}$ this possibility being guaranteed by the scale invariance of the Maxwell equations and the weak dispersion of the refractive indexes of numerous polymers in the visible spectral regime.

Further author information: (Send correspondence to Faiz Ahmad)

Faiz Ahmad: E-mail: fua26@psu.edu

International Workshop on Thin Films for Electronics, Electro-Optics, Energy, and Sensors 2019, edited by

Partha Banerjee, Karl Gudmundsson, Akhlesh Lakhtakia, Guru Subramanyam, Proceedings of SPIE

Vol. 11371, 1137107 - (C) 2019 SPIE · CCC code: 0277-786X/19/\$21 · doi: 10.1117/12.2534592

Proc. of SPIE Vol. 11371 1137107-1 


\section{OPTOELECTRONIC MODEL}

Computational modeling of photovoltaic cells can determine the efficiency loss to achieve the desired color by the rejection of photons in a specific spectral regime. Hence, we implemented and optimized a thin-film $\mathrm{Cu}_{2} \mathrm{ZnSn}\left(\mathrm{S}_{\xi} \mathrm{Se}_{1-\xi}\right)_{4}$ (commonly referred to as CZTSSe) solar cell for two different desired colors: (i) red and (ii) blue-green. Accordingly, either the red part (620-700 nm wavelength) or the bluish-green part (400-550 nm wavelength) of the incoming solar spectrum must be substantially reflected so that it becomes mostly unavailable for the photovoltaic generation of electricity. Therefore, we used an optoelectronic model of CZTSSe solar cells ${ }^{3}$ to optimize them for maximum power conversion efficiency while reflecting either red photons or blue-green photons.

A conventional CZTSSe solar cell has the $\mathrm{MgF}_{2} / \mathrm{AZO} / \mathrm{iZnO} / \mathrm{CdS} / \mathrm{CZTSSe} / \mathrm{Mo}(\mathrm{S}, \mathrm{Se})_{2} / \mathrm{Mo}$ configuration, beginning with a $\mathrm{MgF}_{2}$ layer of thickness $L_{\mathrm{MgF}_{2}}$ as the antireflection coating; an AZO layer of thickness $L_{\mathrm{AZO}}$ as the front contact; an $\mathrm{iZnO}$ layer and a CdS layer of thicknesses $L_{\mathrm{iZnO}}$ and $L_{\mathrm{CdS}}$, respectively, forming a buffer; a CZTSSe layer of thickness $L_{\mathrm{s}}$ as the photovoltaic layer; an $\mathrm{Mo}(\mathrm{S}, \mathrm{Se})_{2}$ layer formed as a consequence of the deposition process; and a Mo back-contact/backreflector of thickness $L_{\mathrm{m}}$. The formation of the $\mathrm{Mo}(\mathrm{S}, \mathrm{Se})_{2}$ layer deleteriously affects the solar-cell performance by adding a series resistance and increasing the back-surface electron-hole pair recombination rate. To avoid the formation of the $\mathrm{Mo}(\mathrm{S}, \mathrm{Se})_{2}$ layer, the introduction of a thin $\mathrm{Al}_{2} \mathrm{O}_{3}$ passivation layer (of thickness $L_{\mathrm{a}}$ ) between the Mo back-contact/backreflector and the CZTSSe photovoltaic layer has been proposed, ${ }^{4}$ and we incorporated this suggestion in our model; see Fig. 1. Also, we replaced the conventional flat back-contact/backreflector with a 1D periodically corrugated one for better light trapping. ${ }^{5,6}$ The period, duty cycle, and height of the periodically corrugated backreflector are denoted by $L_{\mathrm{x}}$, $\zeta \in(0,1)$, and $L_{\mathrm{g}}$, respectively.

The nonhomogeneous bandgap in the CZTSSe layer was taken to be either sinusoidally or linearly graded. ${ }^{3}$ Linearly graded bandgaps of two types were considered: (a) forward graded and (b) backward graded. The linear backward bandgap grading was modeled as

$$
\begin{aligned}
\mathrm{E}_{\mathrm{g}}(z)= & \mathrm{E}_{\mathrm{g}, \text { max }}-A\left(\mathrm{E}_{\mathrm{g}, \max }-\mathrm{E}_{\mathrm{g}, \min }\right) \frac{z-\left(L_{\mathrm{MgF}_{2}}+L_{\mathrm{AZO}}+L_{\mathrm{iZnO}}+L_{\mathrm{CdS}}\right)}{L_{\mathrm{s}}}, \\
& z \in\left[L_{\mathrm{MgF}_{2}}+L_{\mathrm{AZO}}+L_{\mathrm{iZnO}}+L_{\mathrm{CdS}}, L_{\mathrm{MgF}_{2}}+L_{\mathrm{AZO}}+L_{\mathrm{iZnO}}+L_{\mathrm{CdS}}+L_{\mathrm{s}}\right],
\end{aligned}
$$

where $\mathrm{E}_{\mathrm{g}, \min }$ is the minimum bandgap, $\mathrm{E}_{\mathrm{g}, \max }$ is the maximum bandgap, and $A$ is an amplitude (with $A=0$ representing a homogeneous CZTSSe layer). The linear forward bandgap grading was modeled by

$$
\begin{aligned}
\mathrm{E}_{\mathrm{g}}(z)= & \mathrm{E}_{\mathrm{g}, \text { min }}+A\left(\mathrm{E}_{\mathrm{g}, \text { max }}-\mathrm{E}_{\mathrm{g}, \min }\right) \frac{z-\left(L_{\mathrm{MgF}_{2}}+L_{\mathrm{AZO}}+L_{\mathrm{iZnO}}+L_{\mathrm{CdS}}\right)}{L_{\mathrm{s}}}, \\
& z \in\left[L_{\mathrm{MgF}_{2}}+L_{\mathrm{AZO}}+L_{\mathrm{iZnO}}+L_{\mathrm{CdS}}, L_{\mathrm{MgF}_{2}}+L_{\mathrm{AZO}}+L_{\mathrm{iZnO}}+L_{\mathrm{CdS}}+L_{\mathrm{s}}\right] .
\end{aligned}
$$

The sinusoidal bandgap grading was modeled as

$$
\begin{gathered}
\mathrm{E}_{\mathrm{g}}(z)=\mathrm{E}_{\mathrm{g}, \min }+A\left(1.49-\mathrm{E}_{\mathrm{g}, \min }\right) \times\left\{\frac{1}{2}\left[\sin \left(2 \pi K \frac{z-\left(L_{\mathrm{MgF}_{2}}+L_{\mathrm{AZO}}+L_{\mathrm{iZnO}}+L_{\mathrm{CdS}}\right)}{L_{\mathrm{s}}}-2 \pi \psi\right)+1\right]\right\}^{\alpha}, \\
z \in\left[L_{\mathrm{MgF}_{2}}+L_{\mathrm{AZO}}+L_{\mathrm{iZnO}}+L_{\mathrm{CdS}}, L_{\mathrm{MgF}_{2}}+L_{\mathrm{AZO}}+L_{\mathrm{iZnO}}+L_{\mathrm{CdS}}+L_{\mathrm{s}}\right]
\end{gathered}
$$

where $\psi \in[0,1]$ describes a relative phase shift, $K$ is the number of periods in the CZTSSe layer, and $\alpha>0$ is a shaping parameter.

The optoelectronic model was used to determine the effects of the rejection filter on the short-circuit density, the open-circuit voltage, the efficiency, and the fill factor. These parameters were calculated for normally incident unpolarized solar radiation using the rigorous-coupled wave approach for the photon absorption rate and, therefore, the electron-hole-pair generation rate. The transport of electrons and holes in the iZnO/CdS/CZTSSe region was considered using the $1 \mathrm{D}$ drift-diffusion model with the assumption of ideal ohmic front and backcontact. A hybridizable discontinuous Galerkin scheme ${ }^{7,8}$ was used for the drift-diffusion equations. Band-gap varying electron affinity and defect density of states were incorporated in the model, as also were the ShockleyRead-Hall and radiative electron-hole recombination processes. ${ }^{9}$ The differential evolution algorithm ${ }^{10}$ was used to optimize the efficiency for (i) no rejection $(f=0)$, (ii) $50 \%$ rejection $(f=0.5)$, and (iii) $100 \%$ rejection $(f=1.0)$ of either red or blue-green photons. 


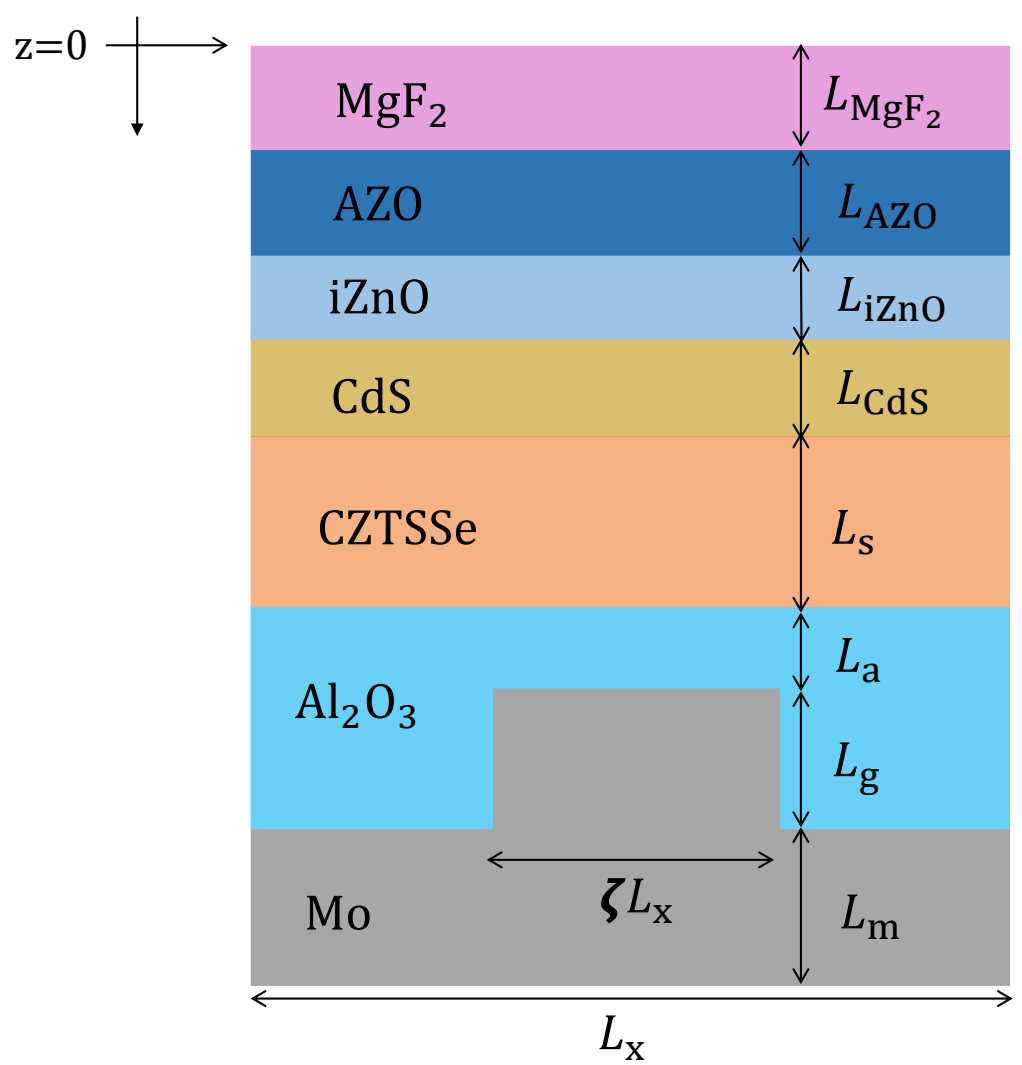

Figure 1. Schematic of the reference unit cell of the CZTSSe solar cell with a 1D periodically corrugated metallic backreflector of period $L_{\mathrm{x}}$ and duty cycle $\zeta \in(0,1)$.

\section{NUMERICAL RESULTS AND CONCLUSION}

First, we considered the CZTSSe layer to have a homogeneous bandgap and the metallic back reflector 1D periodically corrugated backreflector. Values of the short-circuit current density $J_{\text {sc }}$, open-circuit voltage $V_{\text {oc }}$, efficiency $\eta$, and fill factor $F F$ are shown in Table 1 with $f \in\{0,0.5,1.0\}$ of either red or blue-green photons. Also, the percentage relative reduction in efficiency with respect to no rejection $(f=0)$ is provided in the same table. For a conventional 2200-nm-thick CZTSSe solar cell with a 1D periodically corrugated backreflector, the optoelectronic model predicts the optimal solar cell's efficiency without any rejection filter to be $11.8 \%$. The optimal efficiency reduces to $10.7 \%$ if $50 \%$ red photons are rejected and $9.6 \%$ with $100 \%$ rejection of red photons. The optimal efficiency reduces to $10.2 \%$ and $8.7 \%$ with $50 \%$ and $100 \%$ rejection of blue-green photons, respectively.

Next, we considered optimization of linearly nonhomogeneous bandgap solar cells according to Eqs. (1) and (2). The optimal CZTSSe solar cell with a backward linearly nonhomogeneous bandgap [Eq. (1)] was found to be the same as the 2200-nm-thick conventional homogeneous solar cell. For the forward linearly nonhomogeneous bandgap [Eq. (1)], the optimization predicted $A \neq 0$. Values of $J_{\mathrm{sc}}, V_{\mathrm{oc}}, \eta, F F$ and $\% \eta$ reduction are shown in Table 1. For the forward linearly nonhomogeneous bandgap, the efficiency without any rejection filter is $17.0 \%$ with a 2200-nm-thick CZTSSe absorber layer. The efficiency reduces to $15.91 \%$ with $50 \%$ and $14.3 \%$ with $100 \%$ rejection of red photons. The efficiency reduces to $15.2 \%$ and $13.4 \%$ with $50 \%$ and with $100 \%$ rejection of blue-green photons, respectively.

Finally, we considered the sinusoidally nonhomogeneous bandgap described by Eq (3). Values of $J_{\mathrm{sc}}, V_{\mathrm{oc}}, \eta$, $F F$ and $\%$ reduction in $\eta$ are shown in Table 1 . The efficiency without any photon rejection is $21.74 \%$ with an 
Table 1. Values of $J_{\mathrm{sc}}, V_{\mathrm{oc}}, \eta, F F$ and $\%$ reduction in $\eta$ relative to $f=0$ of the optimal CZTSSe solar cell when the CZTSSe layer is either homogeneous or linearly graded according to Eq. (2) or sinusoidally graded according to Eq. (3) and periodically corrugated backreflector. Here, $f \in\{0,0.5,1\}$ denotes the fraction of either red or blue-green photons that could have been absorbed but were rejected by the incorporation of a rejection filter.

\begin{tabular}{|c|c|c|c|c|c|c|c|c|}
\hline Cell type & $\begin{array}{l}\text { Thickness } \\
\text { (nm) }\end{array}$ & $\begin{array}{l}\text { Reflected } \\
\text { color }\end{array}$ & $f$ & $\begin{array}{l}J_{\mathrm{sc}} \\
\left(\mathrm{mA} \mathrm{cm} \mathrm{cm}^{-2}\right)\end{array}$ & $\begin{array}{l}V_{\mathrm{oc}} \\
(\mathrm{V})\end{array}$ & $\begin{array}{l}F F \\
(\%)\end{array}$ & $\begin{array}{l}\eta \\
(\%)\end{array}$ & $\begin{array}{l}\% \text { reduction } \\
\text { of } \eta\end{array}$ \\
\hline \multirow{5}{*}{$\begin{array}{l}\text { Homogeneous } \\
\text { bandgap }\end{array}$} & \multirow[t]{5}{*}{2200} & & 0 & 31.5 & 558 & 70.3 & 11.8 & \\
\hline & & \multirow[t]{2}{*}{ Red } & 0.5 & 29.0 & 536 & 69.0 & 10.7 & 9.3 \\
\hline & & & 1 & 26.3 & 532 & 68.8 & 9.6 & 18.6 \\
\hline & & \multirow{2}{*}{$\begin{array}{l}\text { Blue- } \\
\text { green }\end{array}$} & 0.5 & 28.0 & 534 & 68.6 & 10.2 & 13.5 \\
\hline & & & 1 & 24.3 & 527 & 68.0 & 8.7 & 26.2 \\
\hline \multirow{5}{*}{$\begin{array}{l}\text { Linearly } \\
\text { graded } \\
\text { bandgap }\end{array}$} & \multirow[t]{5}{*}{2200} & & 0 & 36.7 & 628 & 74.0 & 17.0 & \\
\hline & & \multirow[t]{2}{*}{ Red } & 0.5 & 34.8 & 619 & 73.7 & 15.9 & 6.4 \\
\hline & & & 1 & 31.8 & 614 & 73.1 & 14.3 & 15.8 \\
\hline & & \multirow{2}{*}{$\begin{array}{l}\text { Blue- } \\
\text { green }\end{array}$} & 0.5 & 33.5 & 617 & 73.5 & 15.2 & 10.5 \\
\hline & & & 1 & 30.0 & 611 & 72.9 & 13.4 & 21.1 \\
\hline \multirow{5}{*}{$\begin{array}{l}\text { Sinusoidally } \\
\text { graded } \\
\text { bandgap }\end{array}$} & \multirow[t]{5}{*}{870} & & 0 & 37.3 & 772 & 75.2 & 21.7 & \\
\hline & & \multirow[t]{2}{*}{ Red } & 0.5 & 36.1 & 770 & 74.1 & 20.6 & 5.0 \\
\hline & & & 1 & 33.3 & 767 & 73.6 & 18.8 & 13.3 \\
\hline & & \multirow{2}{*}{$\begin{array}{l}\text { Blue- } \\
\text { green }\end{array}$} & 0.5 & 35.2 & 769 & 73.8 & 20.0 & 7.8 \\
\hline & & & 1 & 31.5 & 764 & 73.3 & 17.7 & 18.4 \\
\hline
\end{tabular}

optimal ultrathin $870 \mathrm{~nm}$ CZTSSe layer in Table 1. For this solar cell, the efficiency reduces to $20.6 \%$ with $50 \%$ rejection and $18.8 \%$ with $100 \%$ rejection of red photons. The efficiency reduces to $20.0 \%$ and $17.7 \%$ with $50 \%$ and $100 \%$ rejection of blue-green photons, respectively.

The relative reduction in efficiency is $7.05 \pm 2.05 \%$ with $50 \%$ rejection and $15.80 \pm 2.70 \%$ with $100 \%$ rejection of red photons in Table 1. The analogous figures are $10.40 \pm 2.70 \%$ and $22.35 \pm 3.85 \%$ when blue-green photons are rejected. The main reason for higher efficiency reduction with blue-green rejection filters is that sunlight contains $42 \%$ more blue-green photons than red photons. The efficiency reduction is mainly due to reduction in the short-circuit current density; however, the open-circuit voltage and the fill factor are affected very little.

In conclusion, the emergence and commercialization of solar cells with red or blue-green appearance will enhance the adoption of solar cells for rooftop installation. Our optoelectronic modeling predicts that the reduction in efficiency due to the deployment of a color rejection filter can be compensated by the use of a graded-bandgap semiconductor layer and light-trapping techniques.

Acknowledgments. The authors thank Peter B. Monk (University of Delaware) for continued collaboration and guidance. The research of Faiz Ahmad and Akhlesh Lakhtakia was partially supported by US National Science Foundation (NSF) under grant number DMS-1619901. The research of Tom H. Anderson was partially supported by the US NSF under grant number DMS-1619904. 


\section{REFERENCES}

[1] Lenau, T., Ahmad, F., and Lakhtakia, A., "Towards biomimetic red solar cells," Proceedings of SPIE 10965(1), 109650E (2019).

[2] Saito, A., Murase, J., Yonezawa, M., Watanabe, H., Shibuya, T., Sasaki, M., Ninomiya, T., Noguchi, S., Akai-Kasaya, M., and Kuwahara, Y., "High-throughput reproduction of the Morpho butterfly's specific high contrast blue," Proceedings of SPIE 8339(1), 83390C (2012).

[3] Ahmad, F., Lakhtakia, A., Anderson, T.H., and Monk, P.B., "Towards highly efficient thin-film solar cells with a graded-bandgap CZTSSe layer," preprint.

[4] Liu, F., Huang, J., Sun, K., Yan, C., Shen, Y., Park, J., Pu, A., Zhou, F., Liu, X., Stride, J.A., Green, M.A., and Hao, X., "Beyond $8 \%$ ultrathin kesterite $\mathrm{Cu}_{2} \mathrm{ZnSnS}_{4}$ solar cells by interface reaction route controlling and self-organized nanopattern at the back contact," NPG Asia Materials 9(1), e401 (2017).

[5] Faryad, M., and Lakhtakia, A., "Enhancement of light absorption effi-ciency of amorphous-silicon thin-film tandem solar cell due to multiple surface-plasmon-polariton waves in the near-infrared spectral regime," Optical Engineering 52(8), 087106 (2013).

[6] Khaleque, T., and R. Magnusson, R., "Light management through guided- mode resonances in thin-film silicon solar cells," Journal of Nanophotonics 8(1), 083995 (2014).

[7] Cockburn, B., Gopalakrishnan, J., and Lazarov, R., "Unified hybridization of discontinuous Galerkin, mixed, and continuous galerkin methods for second order elliptic problems," SIAM Journal on Numerical Analysis 47(2), 1319-1365 (2009).

[8] Brinkman, D., Fellner, K., Markowich, P., and Wolfram, M.-T., "A drift-diffusion-reaction model for excitonic photovoltaic bilayers: Asymptotic analysis and a 2-D HDG finite-element scheme," Mathematical Models and Methods in Applied Sciences 23(5), 839-872 (2013).

[9] Adachi, S., [Earth-Abundant Materials for Solar Cells: $\mathrm{Cu}_{2}-\mathrm{II}-\mathrm{IV}-\mathrm{VI}_{4}$ Semiconductors], Wiley, Chicester, United Kingdom, 2015.

[10] Storn, R., and Price, K., "Differential evolution - a simple and efficient heuristic for global optimization over continuous spaces," Journal of Global Optimization 11(4), 341-359 (1997). 